\title{
Probabilistic elastic-plastic fracture mechanics analysis of propagation of cracks in pipes under internal pressure
}

\author{
Mechab Belaïd, Medjahdi Malika, Salem Mokadem, Serier Boualem \\ University of Djillali Liabes, Sidi Bel Abbes, Algeria \\ bmechab@yahoo.fr,mmedjahdi@yahoo.fr,moka_salem@yahoo.fr,boualems@yahoo.fr
}

\begin{abstract}
This study presents a three dimensional finite element method analysis of semi-elliptical surface cracks in pipes under internal pressure load. In the elastic-plastic case, estimates of the J-integral are presented for various ratios including crack depth to pipe thickness $(\mathrm{a} / \mathrm{t})$ and strain hardening index in the (R-O) Ramberg-Osgood (n). Finally, failure probability is accessed by a statistical analysis for uncertainties in loads and material properties, and structural reliability and crack size. The Monte Carlo method is used to predict the distribution function of the mechanical response. According to the obtained results, we note that the stress variation and the crack size are important factors influencing on the distribution function of $\left(\mathrm{J} / \mathrm{J}_{\mathrm{e}}\right)$.
\end{abstract}

KEYwORDS. Failure; Pipe; Fracture mechanics; Monte Carlo method.

\section{open access}

Citation: Mechab, B., Medjahdi, M., Salem, M., Serier, B., Probabilistic elastic-plastic fracture mechanics analysis of propagation of cracks in pipes under internal pressure, Frattura ed Integrità Strutturale, 54 (2020) 202-210.

Received: 27.04.2020

Accepted: 11.08 .2020

Published: 01.10 .2020

Copyright: (C) 2020 This is an open access article under the terms of the CC-BY 4.0, which permits unrestricted use, distribution, and reproduction in any medium, provided the original author and source are credited.

\section{INTRODUCTION}

$\mathrm{E}$ xternal cracks can occur in many structural components of cylindrical form. They are the cause of premature damage in structures such as piping, bolts, pins and reinforcements of aircraft. The fracture prediction and the reliability of such piping systems in various practical applications are primordial given their impact on the economic plan and security [1].

Several authors [2-5] have been studied pipe fracture problems by means of numerical simulation in order to assess the mechanical integrity, taking into account different crack shapes. Raju and Newman [6] have obtained Linear Elastic Fracture Mechanics based stress intensity factors for a wide range of internal and external semi-elliptical surface cracks in a cylinder. The J-integral fracture parameter proposed by [7] has been extensively used in assessing fracture integrity of cracked engineering structures, which undergo large plastic deformation. For elastic-plastic problems, it is interpreted by [8] and [9] as the strength of the asymptotic crack-tip fields and represents the crux of the basis for 'J-controlled' crack growth behaviour. For stability assessment in piping components, it is important to calculate the point of initiation of the crack and to monitor the subsequent crack propagation behaviour [10]. Integrity assurance of secondary system components becomes an important issue relating to impacts on large and early release frequency as well as core damage frequency due to piping failures in nuclear power plant [11]. 
Probabilistic assessments of cracked components are considered in [12]. Several computer programs and benchmark results are available [13-15]. Moreover, probabilistic methods are included in the latest versions of the structural integrity assessment procedures [16-17]. Probabilistic fracture mechanics is a means of quantifying the failure probability resulting from uncertainties in the values of the parameters used to perform a failure assessment of cracked structures through probabilistic analysis techniques [18].

This paper presents a three dimensional finite element method analysis of semi-elliptical surface cracks in pipes under internal pressure load. The effect of the ratios $(\mathrm{a} / \mathrm{t})$ and $(\mathrm{n})$ is presented for evaluating the J-integral. Finally, the Monte Carlo method is used to predict the distribution function of the mechanical response and the possibility of failure.

\section{GEOMETRICAL MODELS}

he geometry of the semi elliptical surface cracks of pipe subjected to internal pressure is represented in Fig. 1. It can be described by the non-dimensional ratios of crack depth to its length (a/c), crack depth to the pipe's wall thickness $(\mathrm{a} / \mathrm{t})$ and mean pipe's radius to its thickness $\left(\mathrm{R}_{\mathrm{m}} / \mathrm{t}\right)$. In this study, $(\beta / \pi)$ is from 0.1 , a/t from 0.3 to 0.7 and $\left(\mathrm{R}_{\mathrm{m}} / \mathrm{t}\right)$ from 20 .

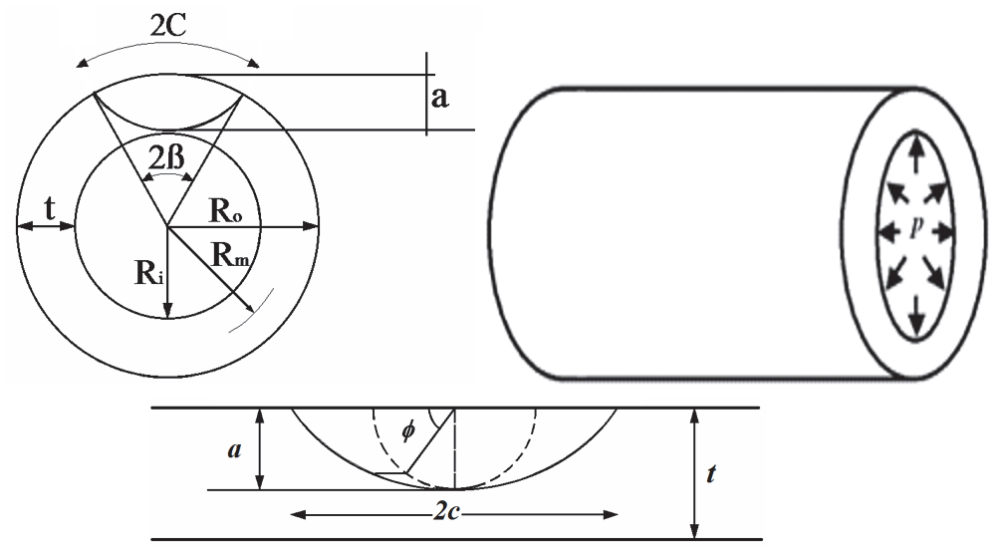

Figure 1: Geometrical model.

\section{MATERIAL MODEL}

he material in the FE analyses is assumed to follow the Ramberg-Osgood (R-O) relation:

$$
\frac{\varepsilon}{\varepsilon_{0}}=\frac{\sigma}{\sigma_{y}}+\alpha\left(\frac{\sigma}{\sigma_{y}}\right)^{n}
$$

where $\mathrm{E} \varepsilon_{0}=\sigma_{\mathrm{y}}$ where $\mathrm{E}$ is the Young's modulus, taken as $\mathrm{E}=200 \mathrm{GPa} ; \sigma_{\mathrm{y}}$ denotes the $0.2 \%$ proof (yield) stress; and $\alpha$ and $\mathrm{n}$ are the R-O parameters. In the present FE analysis, $\alpha$ and $\sigma_{\mathrm{y}}$ are fixed to $\alpha=1$ and $\sigma_{\mathrm{y}}=400 \mathrm{MPa}$. The values of the strain hardening index, n, however, are systematically varied; $n=1$ (elastic), 3, 5 and 10.

\section{FINITE ELEMENT MESH}

he Fig. 2 presents, a typical FE mesh of the cracked pipe. Twenty-node isoparametric quadratic brick elements with reduced integration (C3D20R in ABAQUS) were used to construct a quarter model of the pipe. Values of the Jintegral were extracted using a domain integral method implemented within ABAQUS [19]. In this study, the entire mesh of the model was constructed from two blocks consisting of the pipe's block and the crack's block. A series of tests were undertaken to estimate mesh sensitivity on the results of the J-integral. An initial mesh of 10568 elements in total was employed and refined several times $(17811,25736,34058)$ until reaching 41353 elements. Results of the J-integrals from 
this mesh were practically similar to those of the previous mesh. This was judged adequate to use for all future computations. It is to be noted that for each refined mesh the crack's tip block was refined several times to achieve stable results. The crack tip was modeled with focused elements composed of five contours. Solutions were checked against those employing eight contours, and the results were almost identical.

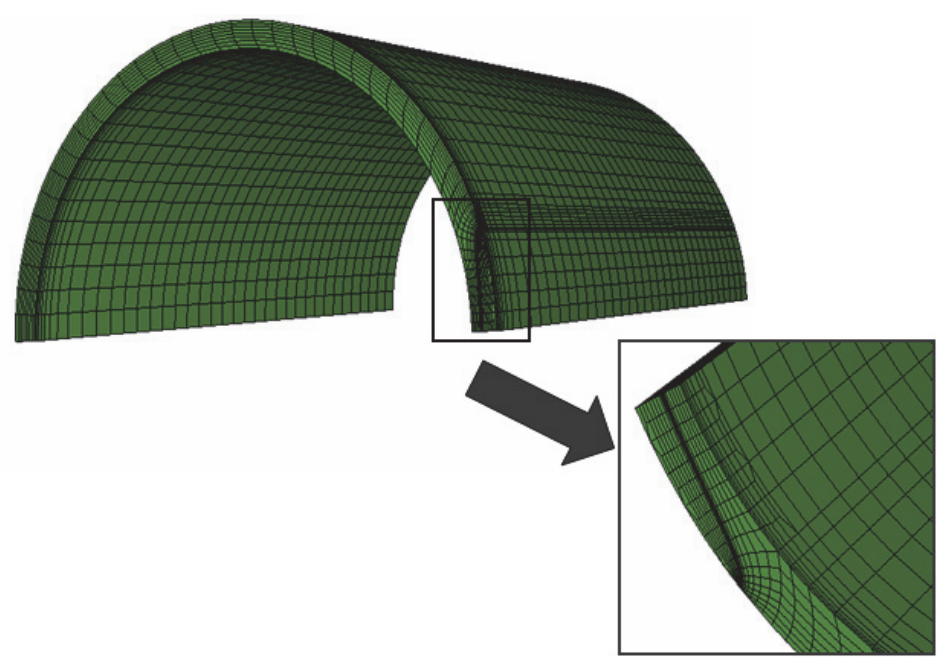

Figure 2: Meshing model of the cylinder.

\section{RESULTS AND DISCUSSION}

$\mathrm{P}$

ipes are considered as one of the important members in the primary heat transport system of power plants. For stability assessment in piping components, it is important to calculate the point of initiation of the crack and to monitor the subsequent crack propagation behaviour [20,21].

Evaluation of the J-integral for cracked welded structures is usually performed by numerical analysis and quick engineering estimation techniques. Using FEM, one can simulate various weld and crack geometries and mis-matching variables.

This work presents a three-dimensional finite element method analysis of a thick cracked pipe in mode I under internal pressure. The elastic FE results (the case of $\mathrm{n}=1$ ) (Ainsworth. RA, [22]) provide the elastic component of the J-integral, Je, from which the stress intensity factor $\mathrm{K}_{\mathrm{I}}$ can be found as:

$$
J_{e}=\frac{K_{I}^{2}}{E^{\prime}}
$$

where $E^{\prime}=E /\left(1-v^{2}\right)$ for plane strain

The elastic-plastic FE analysis provides the values of the J-integral as a function of load, for a given geometry and a type of loading. For the R-O materials (see Eqn. (1)), the fully plastic part of the J-integral, Jp, for pipes with semi elliptical surface cracks can be expressed as:

$$
J_{P}^{F E}=J^{F E}-J_{e}
$$

For the plastic limit internal pressure $\mathrm{P}_{\mathrm{L}}$, the following expression is used in the present work Miller [23]:

$$
P_{L}=\frac{2 \sigma_{y} t}{R_{m}}\left(1-\frac{\beta a / t+2 \sin ^{-1}[a \sin (\beta) / 2 t]}{\pi}\right)
$$




$$
\gamma=1.767\left(\frac{a}{t}\right)\left(\frac{\beta}{\pi}\right)-0.156\left(\frac{a}{t}\right)-0.101\left(\frac{\beta}{\pi}\right)+0.627
$$

The GE/EPRI-type $J$ estimation equations, given in this section, can be used to estimate $J$, for pipes with semi elliptical surface cracks subject to internal pressure. In the GE/EPRI method, as demonstred by Ainsworth[22]. The elastic part of $\mathrm{J}$ in Eqn.(2) cab be expressed as :

$$
J_{e}=\frac{K_{I}^{2}}{E^{\prime}}=\left(\frac{\sigma_{y}^{2}}{E} w\right) h_{1}(n=1)\left[\frac{Q}{Q_{L}}\right]^{2}
$$

where $h_{1}(n=1)$ denotes the value of $h_{1}(n)$ for elastic $(n=1)$ materials. Inserting Eqn. (2) in to Eqn. $(6)$ gives value of $h_{1}(n=1)$ as a function of the crack geometry. Normalizing Eqn. (3) with respect to Eqn. (2) gives:

$$
\frac{J_{P}}{J_{e}}=\alpha \frac{h_{1}(n)}{h_{1}(n=1)}\left[\frac{Q}{Q_{L}}\right]^{n-1}
$$

where

$$
\mathrm{Q}_{\mathrm{L}}=\mathrm{P}_{\mathrm{L}}
$$

Variation of $h_{1}(n) / h_{1}(n=1)$, determined from the FE results, with the strain hardening index $n$ are shown in Fig. 3, for the internal pressure. The results show that the values of $h_{1}(n) / h_{1}(n=1)$ are quite sensitive to $n$.in particular sensitivity of $h_{1}(n) / h_{1}(n=1)$ to $n$ for the case of internal pressure should be noted. For internal pressure, they range from 1 to 50 for $n$ ranging from 1 to 10 .

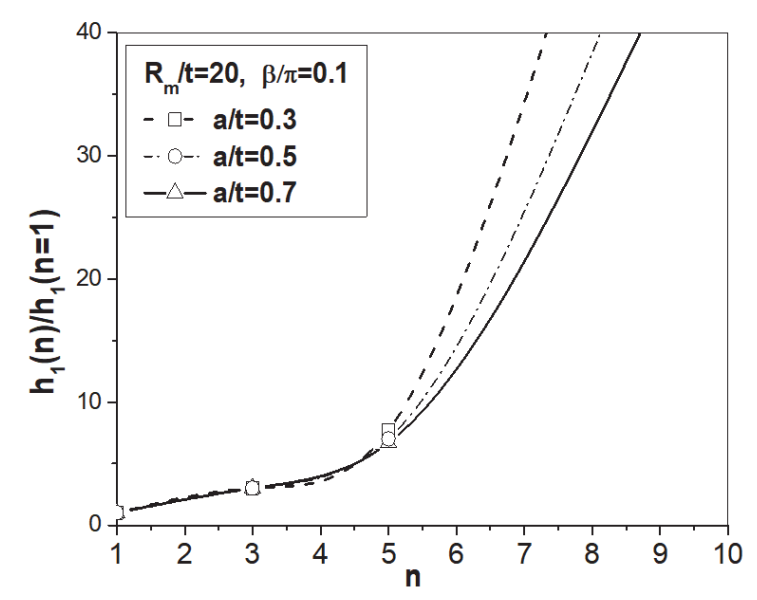

Figure 3: Variation of the $h_{1}(n) / h_{1}(n=1)$ values with $n$, for internal pressure.

The total J-integral can be estimated by adding the elastic component with plasticity correction (R6) [11]:

$$
\begin{aligned}
& \mathrm{J}=\mathrm{J}_{\mathrm{e}}+\mathrm{J}_{\mathrm{p}} \\
& \frac{J}{J_{e}}=\frac{E \varepsilon_{r e f}}{\sigma_{r e f}}+\frac{1}{2}\left(\frac{\sigma_{r e f}}{\sigma_{y}}\right)^{2} \frac{\sigma_{r e f}}{E \varepsilon_{r e f}}
\end{aligned}
$$

where

$$
\sigma_{r e f}=\left(\frac{Q}{Q_{o R}}\right) \sigma_{y}
$$




$$
Q_{o R}=P_{O R}
$$

The Figs. 4 and 5 respectively present the variation of $(\mathrm{J} / \mathrm{Je})$ according to the pressure ratio $\left(\mathrm{P} / \mathrm{P}_{\mathrm{oR}}\right)$ for a different ratio $(\mathrm{a} / \mathrm{t})$ for $\mathrm{n}=5$ and $\mathrm{n}=10$. Compared with the analytical solution of Eqn. (10) found in the literature, it can be noticed that the effect of the ratio $\mathrm{a} / \mathrm{t}$ becomes sensible when the ratio $\left(\mathrm{P} / \mathrm{P}_{\mathrm{oR}}\right)$ exceeds 1.0. This shows a very good correlation between the two methods when the ratio $\mathrm{a} / \mathrm{t}=0.2$ and $\mathrm{a} / \mathrm{t}=0.5$, for $\mathrm{a} / \mathrm{t}=0.7$ the difference is significant especially at high $\left(\mathrm{P} / \mathrm{P}_{\mathrm{oR}}\right)$ but for $n=10$ the difference is significant (see Fig. 5).

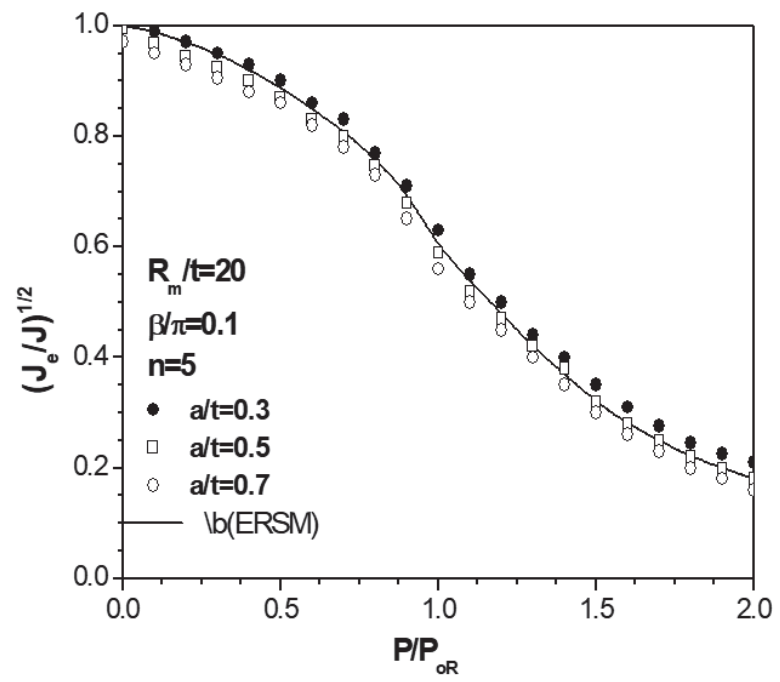

Figure 4: Comparison of the FE J results with those estimated from the proposed ERSM for the internal pressure for $\mathrm{n}=5$

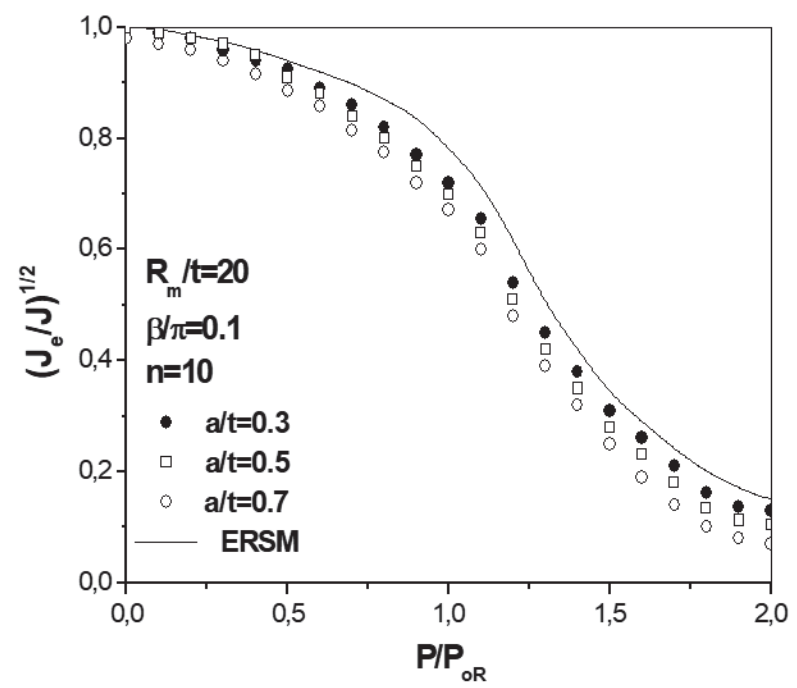

Figure 5: Comparison of the FE J results with those estimated from the proposed ERSM for the internal pressure for $n=10$.

\section{Probabilistic Elastic-Plastic Fracture Mechanic Analysis}

\section{Random parameters and fracture response}

7 he $J$-integral is an appropriate fracture parameter that describes the crack-tip stress and strain fields adequately when there are no constraint effects [24]. Probabilistic models have also been developed to estimate various response statistics and reliability [25]. Using FEM, one can calculate $J$ for any crack geometry and load conditions. However, it is also useful to have simplified estimation methods for routine engineering calculations. Accordingly, the probabilistic EPFM analyses based on both methods have been reported [26,27] 
The uncertainties are related to load estimation, geometrical fluctuations and scatter of material properties; these parameters are modeled by random variables, described by distribution type and parameters (i.e., mean and coefficient of variation COV). For design purpose, the system uncertainties should be controlled in order to avoid unsafe situations. eight random variables are considered to model the thick pipes uncertainties related material properties (Young Modulus (E), Crack length $(a / t)$, mean pipe's radius to its thickness $\left(R_{m} / t\right)$ and Applied stress $(\sigma)$. Tab. 1 indicates the mean values and coefficients of variation for the six selected random variables.

Hence, any relevant fracture response, such as the $(\mathrm{J} / \mathrm{Je})(\mathrm{X})$, should be evaluated by the probability.

$$
\begin{aligned}
& F_{(J / J e)}\left(j_{0}\right) \stackrel{d e f}{=} \operatorname{Pr}\left|(J / J e)(X)<j_{o}\right|=\int_{(J / J e)(X)<j_{0}} f_{x}(x) d x \\
& f_{(J / J e)}=d F_{(J / J e)}\left(j_{o}\right) / d j_{0}
\end{aligned}
$$

Or the probability density function $(\mathrm{PDF})$, where $F_{\left(J / J_{e}\right)}\left(j_{0}\right)$. is the cumulative distribution function of $(\mathrm{J} / \mathrm{Je})$ and $f_{\boldsymbol{x}}(\boldsymbol{x})$ is the known joint probability density function of $\boldsymbol{X}$.

\begin{tabular}{ccc}
\hline Variable & Mean & Coefficient of variation $(\mathrm{COV})$ \\
Young modulus $(\mathrm{E})$ & $200 \mathrm{GPa}$ & $1 \%$ \\
Crack length $(\mathrm{a} / \mathrm{t})$ & $0.3,0.5,0.7$ & $2 \%$ \\
Mean pipe's radius to its thickness $\left(\mathrm{R}_{\mathrm{m}} / \mathrm{t}\right)$ & 20 & $3 \%$ \\
Applied stress $(\sigma)$ & $400 \mathrm{MPa}$ & $2 \%$ \\
\hline
\end{tabular}

Table 1: Random variables and corresponding parameters.

The density function is evaluated by using Monte Carlo method. The basic idea is to draw random samples for the input parameters, then to compute the mechanical response for each sample. When a large number of Monte Carlo samples are achieved, it becomes possible to make statistical analysis of the response sets in order to provide the probability density functions of the $(\mathrm{J} / \mathrm{J}$ e), The failure probability can be obtained by computing the ratio between the number of failed samples and the total number of drawn samples. The sensitivity measures can be also obtained by computing the dispersion of the mechanical response in terms of the scatter of the input parameters. In order to analyze the ductile cracked structures with bonded composite patch by the FORTRAN program, which are developed by the authors: the first program provides the mechanical response by calculating the $\left(\mathrm{J} / \mathrm{J}_{\mathrm{e}}\right)$ distribution and the second program computes the probabilistic response by using Monte Carlo simulations. To achieve a high accuracy of the results, we have carried out $10^{5}$ simulations.
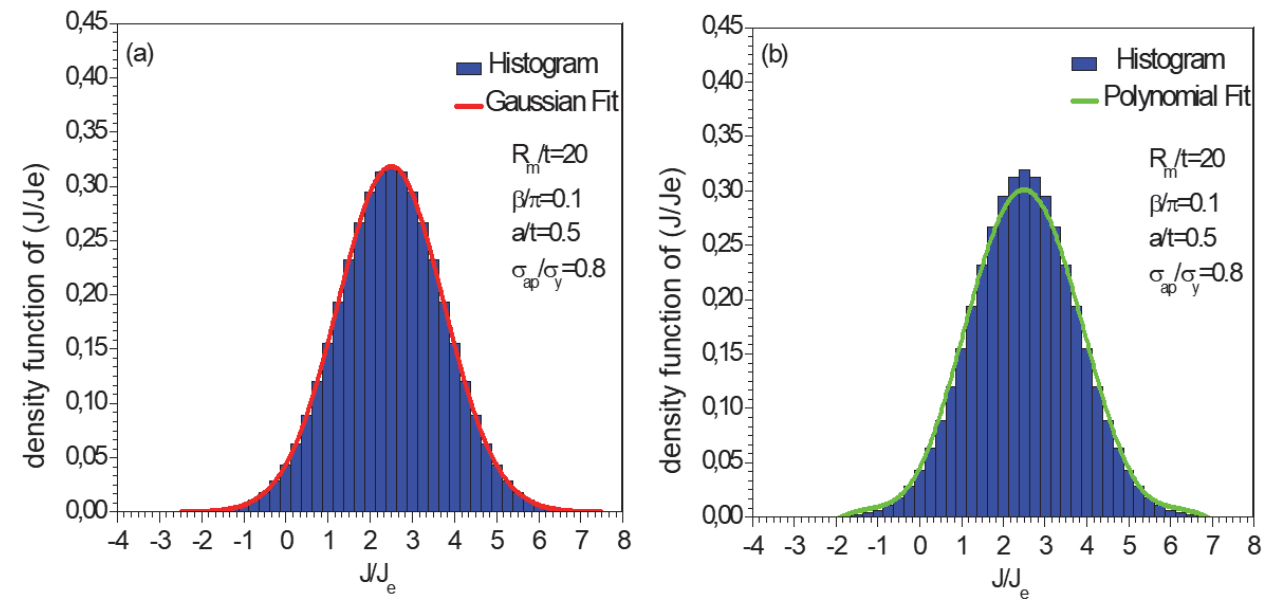

Figure 6: Histogram and probability density function of $\mathrm{J} / \mathrm{J}_{\mathrm{e}}$.

\section{Probabilistic results}

Fig.6 plots the histograms of the $\left(\mathrm{J} / \mathrm{J}_{\mathrm{e}}\right)$ obtained by Monte Carlo simulations. The probability density function (pdf) is obtained by fitting the histogram with theoretical models. Two distribution laws are investigated: Gaussian (Normal law) 
and Polynomial (9th order); from Fig. 6, it can be clearly observed that the three distributions give more or less good approximation of the $\left(\mathrm{J} / \mathrm{J}_{\mathrm{e}}\right.$ ). The polynomial distribution gives a lower mean value than for Gaussian distribution. By comparing these three distributions, we can conclude that the Gaussian law offers an acceptable approximation of the $\left(\mathrm{J} / \mathrm{J}_{\mathrm{e}}\right)$ probability density function, with good estimation of the average (see Fig. 6).

The safety margin $\left(\mathrm{J} / \mathrm{J}_{\mathrm{e}}\right)\left(x_{i}\right)$ is the probabilistic design rule, which defines the plate safety by the condition $\left(\mathrm{J} / \mathrm{J}_{\mathrm{e}}\right)\left(x_{i}\right)>0$ and the plate failure by $\left(\mathrm{J} / \mathrm{J}_{\mathrm{e}}\right)\left(x_{i}\right) \leq 0$. The Figs. 7 and 8 present the cumulative and the probability density of $\left(J / \mathrm{J}_{\mathrm{e}}\right)$ for different values of the stress and length of crack. We noted that when the stress and length of crack is large the value of the probability density of $(\mathrm{J} / \mathrm{J}$ e) is small. It can be seen that the margin increases significantly with the uncertainties related to the load applied and length of crack, leading to larger failure probability, finally, the failure probabilities depend on the load applied and length of crack.
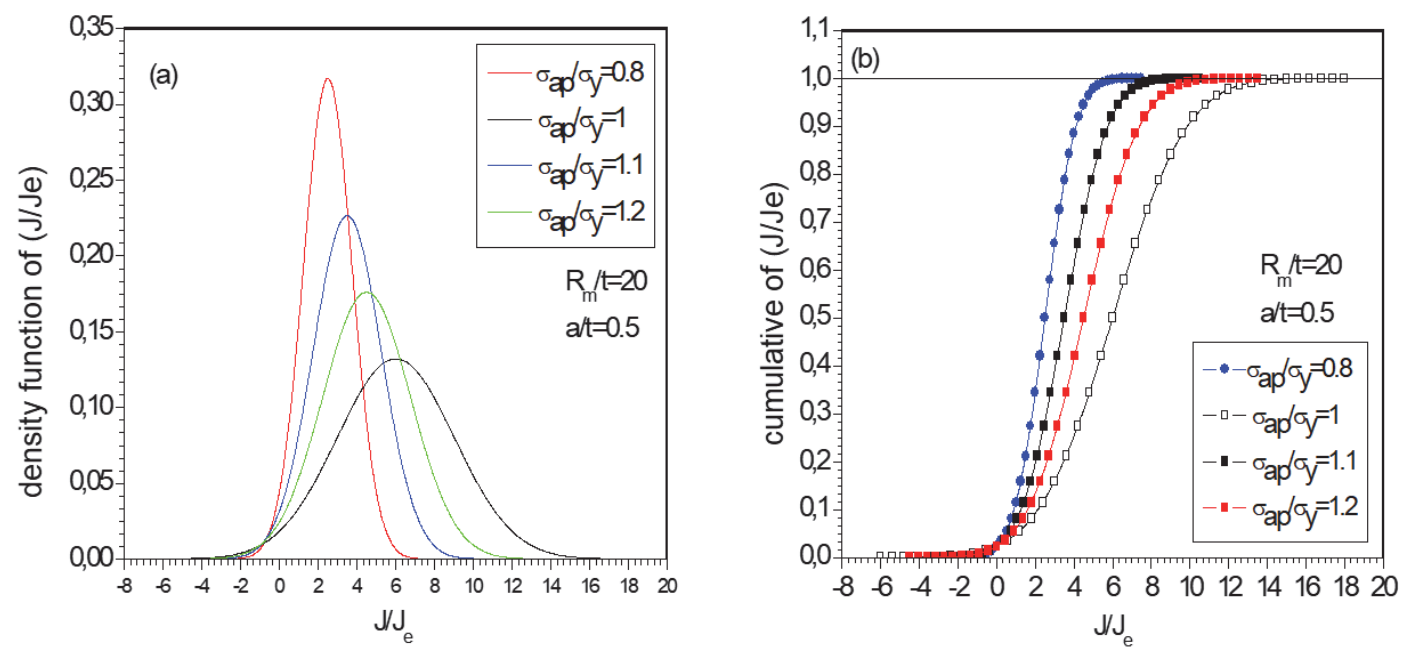

Figure 7: Probability density and the cumulative of $\left(\mathrm{J} / \mathrm{J}_{\mathrm{e}}\right)$ for different values of stress
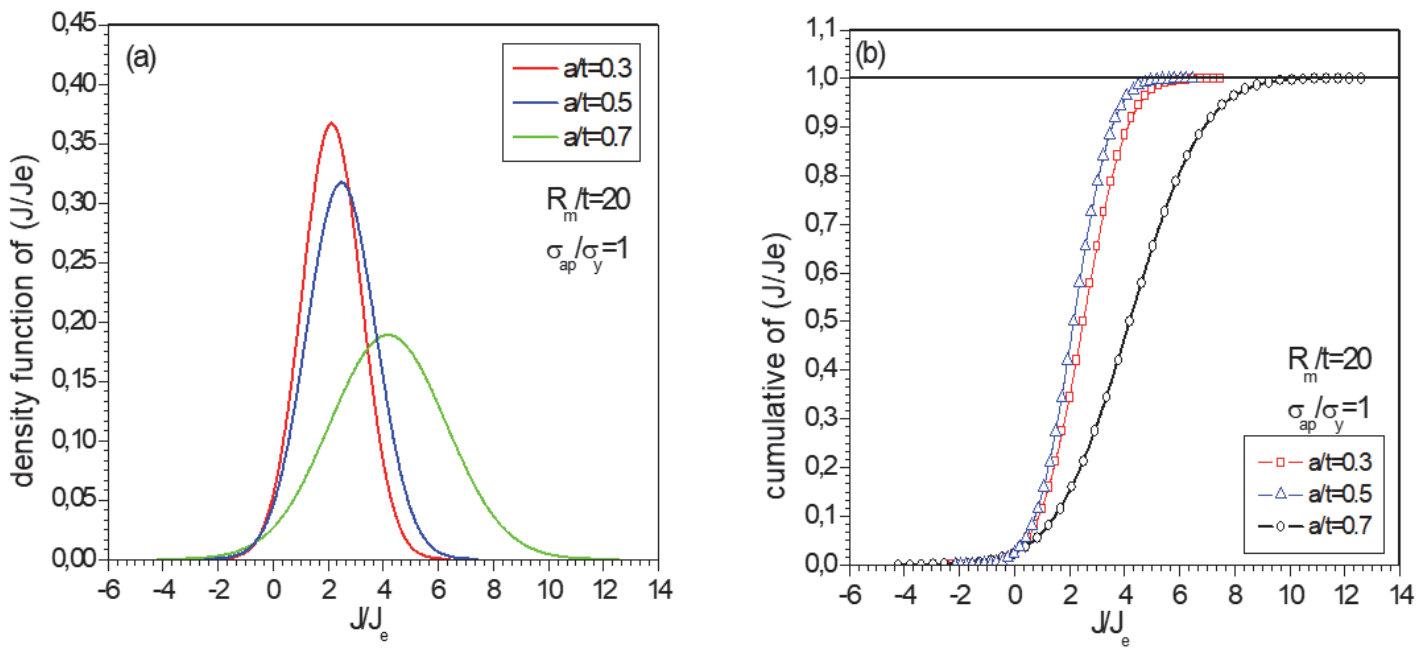

Figure 8: Probability density and the cumulative of $\left(\mathrm{J} / \mathrm{J}_{\mathrm{e}}\right)$ for different values of length of crack.

\section{CONCLUSION}

$\mathrm{P}$

ipelines are important components in a piping system. This study presents a three dimensional finite element method analysis of semi-elliptical surface cracks in pipes under internal pressure load. A probabilistic model was developed for predicting elastic-plastic fracture mechanic response and reliability. The Monte Carlo method is used to predict the distribution function of the mechanical response. According to the obtained results, we note that the stress variation 
and the crack length variations are important factors influencing the distribution function of $(\mathrm{J} / \mathrm{Je})$. The uncertainty in these parameters has a significant effect on increasing the probability of failure of pipe and reducing the durability of structure.

\section{REFERENCES}

[1] Kim, Y.J. Shim, D.J. (2005), Relevance of plastic limit loads to reference stress approach for surface cracked cylinder problems, Int. J. Pres. Ves. Pip. 82, pp. 687-699. DOI:10.1016/j.ijpvp.2005.03.007.

[2] Kim, Y.Jae. Kim, J.S. Park, Y.J. Kim, Y.J. (2004), Elastic-plastic fracture mechanics method for finite internal axial surface cracks in cylinders, Eng. Fract. Mech. 71, pp. 925-944. DOI:10.1016/S0013-7944(03)00159-0.

[3] Mechab, B., Serier, B., Bachir Bouiadjra, B., Kaddouri, K., Feaugas, X. (2011), Linear and non-linear analyses for semielliptical surface cracks in pipes under bending, Int. J. Pres. Ves. Pip. 88, pp. 57-63. DOI: $10.1016 /$ j. ijpvp. 2010.11.001.

[4] Chapuliot, S. (2000), K Formula for pipes with a semi-elliptical longitudinal or circumferential, internal or external surface crack, In: CEA Report CEA-R-5900. CEA/Saclay, France.

[5] Available at: https://inis.iaea.org/collection /NCLCollectionStore/_Public/31/058/31058406.pdf

[6] Marie, S., Chapuliot, S., Kayser, Y., Lacire, M.H, Drubay, B., Barthelet, B., et al. (2007), French RSE-M and RCC-MR code appendices for flaw analysis: presentation of the fracture parameters calculation - part V: elements of validation. Int. J. Pres. Ves. Pip. 84, pp. 687-696. DOI:10.1016/j.ijpvp.2007.05.007.

[7] Raju, I.S., Newman, Jr. (1982), Stress-intensity factors for internal and external surface cracks in cylindrical vessels, J Press Vessel Technol, ASME Trans 104(4), pp. 293-299. DOI:10.1115/1.3264220.

[8] Bach, M. X., Wang.(2013), Constraint-based fracture mechanics analysis of cylinders with internal circumferential cracks, Struct. Eng. Mech. 47(1), pp. 131-147. DOI:10.12989/sem.2013.47.1.131.

[9] Staat, M., Vu, D.K. 2013), Limit analysis of flaws in pressurized pipes and cylindrical vessels, Part II: Circumferential defects. Eng. Fract. Mech. 97, pp. 314-333. DOI:10.1016/j.engfracmech.2012.05.017.

[10] Chattopadhyay, J., Dutta,B.K., Vaze, K.K.(2014), Development of new correlations for improved integrity assessment of pipes and pipe bends, Nucl .Eng. Des, 269, pp. 108-115. DOI:10.1016/j.nucengdes.2013.08.015.

[11] Lee, S.M., Chang, Y.S., Choi , J.B., Kim ,Y.J. (2006). Failure probability assessment of wall- thinned nuclear pipes using probabilistic fracture mechanics, Nucl. Eng. Des, 236, pp. 350-358. DOI:10.1016 /j.nucengdes.2005. 09.008.

[12] R6 (2001). Assessment of the Integrity of Structures Containing Defects, Revision 4. British Energy Generation Ltd, Gloucester.

[13] Qian, G., Niffenegger, M., Karanki D.R., Li, S. (2013). Probabilistic leak before- break analysis with correlated input parameters, Nucl. Eng. Des. 254, pp. 266-271. DOI: 10.1016/S0308-0161(96)00034-8.

[14] Tee, K.F., Khan, L.R., Chen, H.P. (2013). Probabilistic failure analysis of underground flexible pipes, Struct. Eng. Mech. 47(2), pp. 167-183. DOI: 10.12989/sem.2013.47.2.167.

[15] Rahman, S. (1995). A stochastic model for elastic-plastic fracture analysis of circumferential through-wall-cracked pipes subject to bending, Eng. Fract. Mech. 52, pp. 265-288. DOI:10.1016/0013-7944(95)00018-Q.

[16] Rahman, S. (2000). Probabilistic elastic-plastic fracture analysis of circumferentially cracked pipes with finite-length surface flaws, Nucl. Eng. Des. 195, pp. 239-260. DOI:10.1016/S0029-5493(99)00214-9.

[17] Cizelj, L., Mavko, B., Riesch, Oppermann, H. (1994). Application of first and second order reliability n methods in the safety assessment of cracked steam generator tubing, Nucl. Eng Des, 147, pp. 359-368. DOI: 10.1016/0029-5493(94)90218-6.

[18] Sandvik, A., Østby, E., Thaulow, C. (2006). Probabilistic fracture assessment of surface cracked pipes using strain-based approach, Eng. Fract. Mech. 73, pp. 1491-1509. DOI: 10.1016/j.engfracmech.2006.01.026.

[19] Rahman, S. (1997). Probabilistic fracture analysis of pipes with circumferential flaws, Int. J. Pres. Ves. Pip. 70, pp. 223236. DOI: 10.1016/S0308-0161(96)00034-8.

[20] ABAQUS (1998), ABAQUS Standard/User's Manual, Version 5.8-1. Hibbit Karlsson \& Sorensen, Inc., Pawtucket, RI, USA.

[21] Kim, Y.J., Kim, J.S., Lee, Y.Z., Kim, Y.J. (2002). Non-linear fracture mechanics analyses of part circumferential surface cracked pipes, Int. J. Fract., 116, pp. 347-375. DOI: 10.1023/A:1020779611803.

[22] Peng, J., Zhou, C.Y., Xue, J.L., Dai, Q., He, X.H. (2011). Safety assessment of pipes with multiple local wall thinning defects under pressure and bending moment, Nucl. Eng. Des, 241, pp. 2758-2765.

DOI: $10.1016 /$ j.nucengdes.2011.06.030. 
[23] Ainsworth, R.A. (1984). The assessment of defects in structures of strain hardening materials, Eng. Fract. Mech. 19, pp. 633-642. DOI: 10.1016/0013-7944(84)90096-1.

[24] Miller, A.G. (1988). Review of limit loads of structures containing defects, Int. J. Pres. Ves. Pip. 32, pp. 191-327. DOI: $10.1016 / 0308-0161(88) 90073-7$.

[25] Mechab, B., Chioukh, N., Mechab, Boubaker., Serier, B. (2018). Probabilistic Fracture Mechanics for Analysis of Longitudinal Cracks in Pipes Under Internal Pressure, Journal of Failure Analysis and Prevention, 18(6), pp. $1643-651$. DOI: $10.1007 / \mathrm{s} 11668-018-0564-8$.

[26] Salem.B., Mechab, B., Berrahou, M., Bachir Bouiadjra, B., Serier, B. (2019). Failure Analyses of Propagation of Cracks in Repaired Pipe Under Internal Pressure, Journal of Failure Analysis and Prevention. 19(1), pp 212-218. DOI:10.1007/s11668-019-00592-3.

[27] Rahman, S., Brust, F.W. (1997), Approximate methods for predicting J-integral of a circumferentially surface-cracked pipe subject to bending, Int. J. Fract. 85, pp. 11-130. DOI:10.1023/A:1007322018722.

[28] Rahman, S., Ghadiali, N., Paul, D., Wilkowski, G. (1995), Probabilistic Pipe Fracture Evaluations for Leak-RateDetection Applications, NUREG:CR-6004. U.S. Nuclear Regulatory Commission, Washington, DC.

DOI:10.2172/50938. 